\title{
Pyrotinib enhances the radiosensitivity of HER2-overexpressing gastric and breast cancer cells
}

\author{
TINGTING HUANG, XIAOXIAO LUO, BILI WU, PING PENG, YUHONG DAI, \\ GUANGYUAN HU, HONG QIU and XIANGLIN YUAN \\ Department of Oncology, Tongji Hospital, Tongji Medical College, \\ Huazhong University of Science and Technology, Wuhan, Hubei 430030, P.R. China
}

Received March 8, 2020; Accepted August 31, 2020

DOI: $10.3892 /$ or.2020.7820

\begin{abstract}
The overexpression or amplification of HER2 has been observed in a significant proportion of both gastric cancer (GC) and breast cancer (BC) cases. Pyrotinib is an irreversible dual (EGFR/HER2) tyrosine kinase inhibitor (TKI), newly evaluated for the treatment of HER2-overexpressing cancer types. As radiotherapy (RT) serves a crucial role in controlling the local recurrence of GC and $\mathrm{BC}$, the present study investigated the impact of pyrotinib on the irradiation response. The current results demonstrated that pyrotinib enhanced the radiosensitivity of HER2-overexpressing $\mathrm{GC}$ and $\mathrm{BC}$ cells in vitro and in vivo. In both NCI-N87 and SKBR3 cells, pyrotinib suppressed the irradiation-induced HER2 nuclear transport. Furthermore, pyrotinib increased DNA damage induced by irradiation in both cancer cell lines. Pyrotinib also enhanced the cytotoxicity of docetaxel, which may provide a novel strategy for potential drug combinations. Thus, pyrotinib is a promising irradiation sensitizer in patients with HER2-overexpressing GC and BC. The present results provide a theoretical foundation for further clinical evaluation of pyrotinib.
\end{abstract}

\section{Introduction}

Gastric cancer (GC) and breast cancer (BC) are two of the most common malignant cancer types worldwide, particularly in China. In 2015, GC caused $\sim 498,000$ mortalities

Correspondence to: Professor Xianglin Yuan or Professor Hong Qiu, Department of Oncology, Tongji Hospital, Tongji Medical College, Huazhong University of Science and Technology, 1095 Jiefang Avenue, Wuhan, Hubei 430030, P.R. China

E-mail: xlyuan1020@163.com

E-mail: tjqiuhong@163.com

Abbreviations: TKI, tyrosine kinase inhibitor; GC, gastric cancer; BC, breast cancer; RT, radiotherapy; STR, Short Tandem Repeat; PE, plating efficiency; SF, surviving fraction; SER, sensitizer enhancement ratio; DSBs, double-strand breaks

Key words: pyrotinib, radiosensitivity, HER2, GC, BC and 679,000 new cases (1). Among women $\leq 45$ years of age, $\mathrm{BC}$ remains the leading cause of cancer-related mortality, followed by lung cancer (1). Due to cancer recurrence and metastasis, numerous patients fail treatment despite improvements in GC and BC therapy. In patients with GC and BC, radiotherapy (RT) serves a crucial role in controlling local recurrence (2). In the past decades, great progress has been made to improve the ability to select appropriate patients, and thus, maximize clinical benefits, while minimizing toxicity and disease burden (2). However, limitations persist despite the appropriate use of RT. Intrinsic or acquired radioresistance and non-specific toxicity limit the efficacy of RT (2). To overcome these shortcomings, increased efforts have been made to discover an effective radiosensitizer characterized by higher efficacy and lower toxicity.

HER2 is upregulated in $13-23 \%$ of GC and $15-30 \%$ of BC cases (3-5). HER2 acts as an oncogene in different cancer types, most likely because amplification of this gene consistently results in HER2 upregulation and the acquisition of beneficial properties of malignant cells (6). Moreover, accumulating evidence has revealed that HER2 is involved in radioresistance $(7,8)$. Previous studies have reported that HER2-targeting agents, including trastuzumab, lapatinib and afatinib, could be utilized to sensitize HER2-overexpressing cancer cells to RT by inhibiting signaling pathways inducing radioresistance (9-11). The combination of RT and trastuzumab has been applied in clinical practice and has been investigated mainly as an adjuvant therapy (12). The side effects observed with the concurrent use of trastuzumab and locoregional RT in $\mathrm{BC}$ are acceptable, demonstrating satisfactory outcomes (12); however, longer follow-ups are required to further identify these effects. The mechanism of HER2 induced-radioresistance in cancer cells also remains unknown. Previous studies have revealed that HER2 transport from membranes to nuclei contributes to radioresistance, and the survival of irradiated HER2-overexpressing cancer cells is decreased after inhibiting this pathway $(13,14)$.

Not all patients with HER2 overexpression benefit from trastuzumab. For instance, certain patients develop resistance to trastuzumab after 1 year, even those who achieved an initial reaction to this drug (15). Similarly, primary and acquired resistance to lapatinib, a reversible dual tyrosine kinase inhibitor (TKI) of EGFR and HER2, remains a significant clinical 
problem (16). To further enhance HER2 inhibition, pyrotinib, a novel irreversible dual (EGFR/HER2) TKI, has been evaluated for the treatment of HER2-overexpressing cancer types. Compared with trastuzumab and lapatinib, pyrotinib effectively overcomes drug resistance triggered by EGFR or HER2 mutations, which is due to the covalent binding between cysteine residues of the receptor and electrophilic groups of pyrotinib $(17,18)$. Currently, enhancing the sensitivity of cancer cells to irradiation by targeting the HER family has been approved as a novel method to potentiate the therapeutic efficacy of irradiation (19). Although the antitumor effect of pyrotinib has been previously reported (20), the role of pyrotinib in sensitizing HER2-overexpressing cancer cells to irradiation needs to be further elucidated.

The present study hypothesized that pyrotinib may be a promising irradiation sensitizer in patients with HER2-overexpressing GC and BC. The current study aimed to investigate the radiosensitizing effect of pyrotinib in HER2-overexpressing GC and BC cell lines, as well as in xenograft models. Additionally, the potential mechanism involving HER2 nuclear transport was identified.

\section{Materials and methods}

Cell culture and reagents. Human GC cell lines (NCI-N87 and MKN28) and human BC cell lines (SKBR3 and MCF7) were purchased from the Type Culture Collection of the Chinese Academy of Sciences. All cell lines were cultured in RPMI-1640 medium (Gibco; Thermo Fisher Scientific, Inc.) supplemented with 10\% FBS (Gibco; Thermo Fisher Scientific, Inc.) at $37^{\circ} \mathrm{C}$ with $5 \% \mathrm{CO}_{2}$. All cell lines were authenticated using Short Tandem Repeat profiles. Pyrotinib was gifted by Hengrui Medicine Co., Ltd. The cytotoxic drugs fluorouracil, cisplatin, docetaxel and epirubicin were obtained from Sigma-Aldrich (Merck KGaA). All drugs were dissolved in DMSO at appropriate concentrations (pyrotinib at $100 \mathrm{mg} / \mathrm{ml}$, fluorouracil at $100 \mathrm{mM}$, cisplatin at $10 \mu \mathrm{M}$, docetaxel at $100 \mu \mathrm{M}$ and epirubicin at $10 \mu \mathrm{M}$ ).

$X$ irradiation. The irradiation of cancer cells and mice was performed using an RS2000 X-ray Biological Research Irradiator (160 kV; 25 mA; 3-mm copper filter; Rad Source Technologies, Inc.).

Western blotting. After treatment, the whole-cell protein was extracted by lysing cells with RIPA buffer, which was supplied with a complete protease inhibitor cocktail (Roche Diagnostics, Inc.). Nuclear protein was extracted using the Nuclear and Cytoplasmic Protein Extraction kit (cat. no. P0028; Beyotime Institute of Biotechnology) following the manufacturer's instructions, at $0,0.25,0.5,1$ and $6 \mathrm{~h}$ after irradiation. The Enhanced BCA Protein Assay kit (cat. no. P0010; Beyotime Institute of Biotechnology) was used to determine protein concentrations. An equal amount of protein $(20 \mu \mathrm{g})$ was electrophoresed in 8-10\% SDS-PAGE and then transferred to the PVDF membrane (cat. no. IPVH00010; EMD Millipore). After blocking with 5\% non-fat milk at room temperature for $1 \mathrm{~h}$, the membranes were incubated with the primary antibody diluted at 1:1,000 overnight at $4^{\circ} \mathrm{C}$. Antibodies against HER2 (cat. no. 2165), $\gamma$-H2A histone family member X $(\gamma-\mathrm{H} 2 \mathrm{AX}$; cat. no. 9718), phosphorylated (p)-Akt (cat. no. 4060), Akt (cat. no. 4691), p-MAPK (cat. no. 4370), MAPK (cat. no. 4695) were purchased from Cell Signaling Technology, Inc. Primary antibodies against GAPDH (cat. no. A00227) and Lamin B1 (cat. no. BA1228) were purchased from Wuhan Boster Biological Technology, Ltd. After washing three times, each for $10 \mathrm{~min}$, in TBS-0.1\% Tween-20, the membranes were incubated with the secondary antibody (1:5,000; cat. no. A0208; Beyotime Institute of Biotechnology) labeled with horseradish peroxidase for $1 \mathrm{~h}$ at $37^{\circ} \mathrm{C}$. The blots were visualized using the Enhanced Chemiluminescence Detection kit (cat. no. 32209; Thermo Fisher Scientific, Inc.).

Immunofluorescence. Cancer cells $\left(5 \times 10^{4}\right.$ cells $\left./ \mathrm{ml}\right)$ were cultured on slips and fixed with $4 \%$ paraformaldehyde for 10-20 min at room temperature. After washing in PBS, the cells were permeabilized with $0.1 \%$ Triton X-100, blocked using 5\% BSA (Gibco; Thermo Fisher Scientific, Inc.) for $1 \mathrm{~h}$ at room temperature and incubated with primary antibodies overnight at $4{ }^{\circ} \mathrm{C}$. Primary antibodies used were as follows: Anti-HER2 (1:200; cat. no. 2165; Cell Signaling Technology, Inc.) and $\gamma$-H2AX (1:200; cat. no. 9718; Cell Signaling Technology, Inc.). After washing in PBS three times, the cells were incubated with FITC-conjugated anti-rabbit secondary antibody (1:500; cat. no. BA1105; Wuhan Boster Biological Technology, Ltd.) for $1 \mathrm{~h}$ at room temperature in the dark. DAPI stained for $3 \mathrm{~min}$ at room temperature and was used for nuclear localization, as well as to assess the quality of the experiment. The slides were washed with PBS until the excess DAPI was removed. After drying, the slides were sealed with coverslips and mounting medium. Finally, the cells were visualized with fluorescent microscope (magnification, x200).

Cell viability assay. To assess cell viability, cells were seeded in 96-well plates at a density of 5,000 cells per well and cultured overnight to grow adhering to the wall. Then, the cells were treated with the indicated concentrations of drugs and/or the indicated dose of irradiation at $37^{\circ} \mathrm{C}$. An increasing dose of pyrotinib $(0,0.1,1,10,100$ and $1,000 \mu \mathrm{g} / \mathrm{ml})$ was used to examine the sensitivity of GC and BC cells to pyrotinib. After $48 \mathrm{~h}$, the original culture media were removed. The cells of each well were washed with PBS and maintained in fresh culture media with $10 \%$ Cell Counting Kit-8 reagent (CCK-8; cat. no. AR1160; Wuhan Boster Biological Technology, Ltd.) for another $1 \mathrm{~h}$ at $37^{\circ} \mathrm{C}$ according to the manufacturer's instructions. The absorbance of viable cells was measured using a microplate reader at $450 \mathrm{~nm}$. Each treatment was performed in $\geq 3$ replicate wells.

Clonogenic survival assay. Cancer cells were cultured in 6-well plates at different densities $(100,200,600,2,000$ and 6,000 cells/per well). Following pretreatment with pyrotinib $\left(0.1 \mu \mathrm{g} / \mathrm{ml}, 37^{\circ} \mathrm{C}\right.$ for $\left.24 \mathrm{~h}\right)$, cells were exposed to irradiation at different radiation doses $(0,2,4,6$ and 8 Gy). After incubation for 14-20 days, cells were fixed with anhydrous methanol for $15 \mathrm{~min}$ at room temperature and stained with $0.1 \%$ crystal violet for $20-30 \mathrm{~min}$ at room temperature. Colonies counting $>50$ cells were considered as surviving clones. The plating efficiency (PE) and surviving fraction (SF) were calculated as follows: $\mathrm{PE}=$ mean colony number in 
un-irradiated controls/number of seeded cells. $\mathrm{SF}=$ mean colony number/(number of cells seeded x PE). A Multi-target single-hit model $\left[\mathrm{S}=1-\left(1-\mathrm{e}^{-\mathrm{D} / \mathrm{D} 0}\right)^{\mathrm{N}}\right]$ was used to calculate $\mathrm{D}_{0}$ the average irradiation dose of lethal exposure), with the sensitizer enhancement ratio (SER) determined as follows, $\mathrm{SER}=\mathrm{D}_{0}$ of combination treatment $/ \mathrm{D}_{0}$ of irradiation treatment alone.

Measurement of apoptosis. Quantification of cell apoptosis was performed using the Annexin V-FITC/PI Apoptosis Detection kit (cat. no. KGA105; Nanjing KeyGen Biotech Co., Ltd.) following the manufacturer's protocol. After treatment, cells were trypsinized before collection and suspended in $300 \mu \mathrm{l}$ binding buffer. Then, $5 \mu \mathrm{l}$ Annexin V-FITC and $5 \mu \mathrm{l}$ PI were added to each sample. The cell samples were incubated in the dark for $15 \mathrm{~min}$ at room temperature, detected using flow cytometry (BD LSRFortessa; BD Biosciences), and analyzed using FlowJo software version 10.7 (FlowJO LLC). The apoptotic rate was calculated as the percentage of early + late apoptotic cells.

Cell cycle distribution. Cell cycle distribution was detected using the PI/RNase buffer (cat. no. KGA512; Nanjing KeyGen Biotech Co., Ltd.) following the manufacturer's protocol. NCI-N87 and SKBR3 cells were treated with pyrotinib $(0.1 \mu \mathrm{g} / \mathrm{ml})$, irradiation (4 Gy) or the combination of pyrotinib and irradiation. After treatment, cells were harvested via trypsinization, washed with PBS and fixed with $70 \%$ ethanol for $20 \mathrm{~min}$ at $4^{\circ} \mathrm{C}$. Then, cell samples were suspended in RNase buffer with PI, shielded from light for $30 \mathrm{~min}$ at room temperature and analyzed via flow cytometry (BD LSRFortessa; BD Biosciences) and FlowJo software version 10.7 (FlowJo LLC).

Xenograft models. Animal experiments were performed according to the guidelines of, and were approved by the Ethical Committee of Tongji Hospital, Tongji Medical College, Huazhong University of Science and Technology (permit no. TJ2015A). Female nude (BALB/c nu-nu; age, 4-6 weeks; weight, 12-15 g) mice were obtained from Charles River, Ltd., and fed under pathogen-free conditions (temperature $26-28^{\circ} \mathrm{C}$; humidty, $40-60 \%$; $10 \mathrm{~h}$ light $/ 14 \mathrm{~h}$ dark cycle; provided with food and water by staff). Tumor cells $\left(1 \times 10^{6}\right.$; $100 \mu \mathrm{l}$ ) mixed with $100 \mu \mathrm{l}$ Matrigel were subcutaneously inoculated into the rear flank. Mice were randomly divided into four groups (6-8 mice per group): Control, pyrotinib $(10 \mathrm{mg} / \mathrm{kg} /$ day; intraperitoneal injection) only, irradiation (10 Gy on day 8) only and a combination of pyrotinib $(10 \mathrm{mg} / \mathrm{kg} / \mathrm{day}$; intraperitoneal injection) and irradiation (10 Gy on day 8), when xenograft tumors grew to $\sim 5$-mm in diameter. During tumor treatment with irradiation, the rest of the body of mouse was shielded using a lead shield. The body weights of the mice and xenograft tumor volumes were measured thrice weekly. To calculate the tumor volume, the following equation was applied: Tumor volume $\left(\mathrm{mm}^{3}\right)=$ length $\mathrm{x}$ width $2 / 2$. A total of 3 weeks after treatment, the mice were executed via cervical vertebra dislocation. The mortality of the mice was verified by cardio-respiratory arrest, absence of nervous reflexes and muscular flaccidity. The tumors were harvested for analysis.

Tumor tissues were immersed in $4 \%$ paraformaldehyde for $4 \mathrm{~h}$ at room temperature, placed in processing cassettes, dehydrated via a serial alcohol gradient $(50,70,85,95$ and $100 \%$ ) and embedded in paraffin wax blocks. Then, $5 \mu \mathrm{m}$-thick tissue sections were dewaxed in xylene, rehydrated via decreasing concentrations of ethanol and washed in PBS. The sections were stained with hematoxylin for $10 \mathrm{~min}$ and eosin for $30 \mathrm{sec}$ both at room temperature. After staining, sections were dehydrated using increasing concentrations of ethanol and xylene. The slides were observed under a light microscope (magnification, x200).

Statistical analysis. Statistical analyses were performed with the SPSS software version 23.0 (IBM Corp,). Each experiment in the present study was performed $\geq 3$ times. Data are presented as the mean $\pm \mathrm{SD}$. Statistical differences between two groups were calculated using a two-tailed Student's t-test. Tukey's test was used for the comparison of multiple groups following one-way ANOVA. $\mathrm{P}<0.05$ was considered to indicate a statistically significant difference.

\section{Results}

HER2-overexpressing GC and BC cells are selectively sensitive to pyrotinib inhibition. To identify HER2-overexpressing $\mathrm{GC}$ and $\mathrm{BC}$ cells, the degree of HER2 protein expression was evaluated in two GC cell lines (NCI-N87 and MKN28) and two BC cell lines (SKBR3 and MCF-7). Western blotting results demonstrated that NCI-N87 and SKBR3 cells had upregulated HER2 protein expression, while the remaining cell lines did not overexpress HER 2 protein (Fig. 1A). Furthermore, it was observed that HER2 was mainly located on cell membranes (Fig. 1B).

To examine the sensitivity of GC and $\mathrm{BC}$ cells to pyrotinib, each cell line was exposed to increasing doses of pyrotinib. Compared with HER2 non-overexpressing GC and BC cells, NCI-N87 and SKBR3 cells displayed sensitivity to pyrotinib (Fig. 1C).

Pyrotinib enhances the radiosensitivity of HER2overexpressing GC and BC cells. After treatment for $48 \mathrm{~h}$, pyrotinib induced the dose-dependent proliferative inhibition of NCI-N87 and SKBR3 cells (Fig. 1C). Pyrotinib at $0.1 \mu \mathrm{g} / \mathrm{ml}$ was unable to suppress cell viability significantly, and the survival rate of cancer cells was $>80 \%$. Therefore, the drug concentration of $0.1 \mu \mathrm{g} / \mathrm{ml}$ was selected for further in vitro experiments. The combination of irradiation and pyrotinib significantly inhibited proliferation (Fig. 2A) and clonogenic survival in NCI-N87 and SKBR3 cells (Fig. 2B). Compared with cells treated with irradiation alone, pretreatment of pyrotinib decreased colony formation of cancer cells after irradiation, suggesting that pyrotinib enhanced the radiosensitivity of NCI-N87 and SKBR3 cells (SER=1.375 and 1.326; Fig. 2B). As pyrotinib sensitized HER2-overexpressing GC and BC cells to irradiation, this drug may function as a promising radiosensitizer in indicated patients, and its targeted toxicity toward HER2-overexpressing cancer cells may augment the therapeutic effect.

Pyrotinib augments irradiation response in HER2overexpressing tumor xenografts. Based on the in vitro radiosensitizing effects in HER2-overexressing cancer cells, 

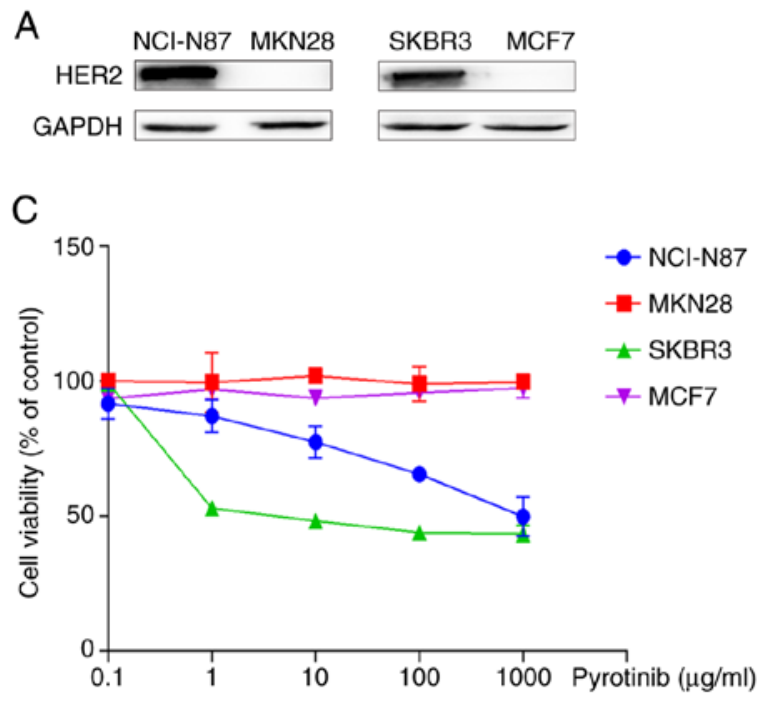

B
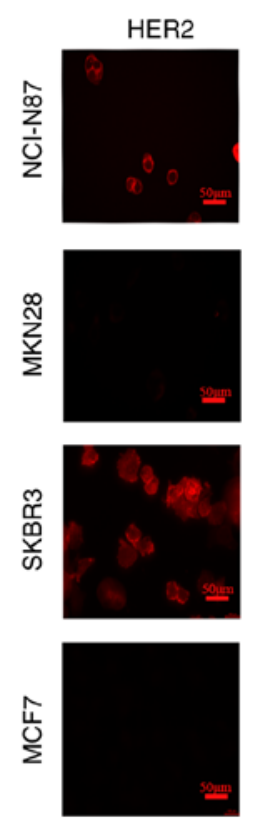
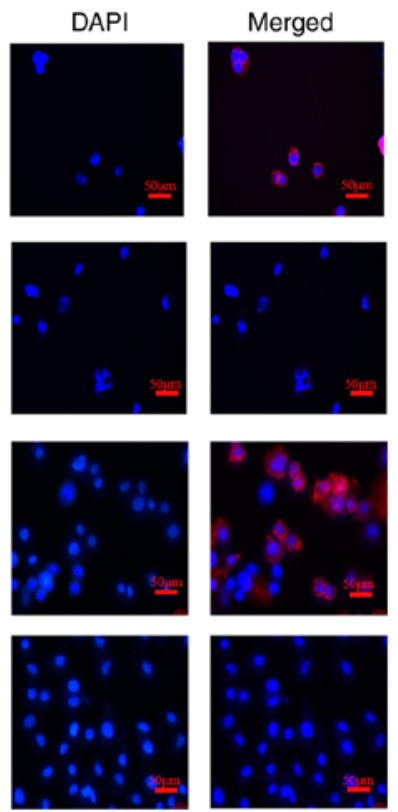
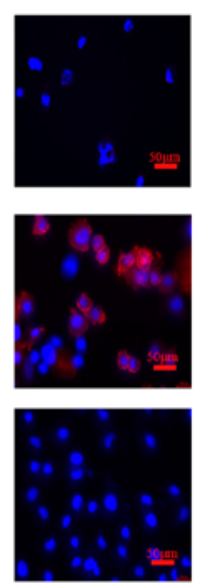

Figure 1. HER2 overexpression predicts pyrotinib sensitivity in GC and BC cells. (A) Detection the expression of HER2 in GC and BC cells via western blotting. (B) Immunofluorescence confirming the expression and location of HER2 protein in GC and BC cell lines. Red fluorescence represents the expression of HER 2 and blue fluorescence of DAPI represents nuclear localization. (C) Cell viability was examined using a Cell Counting Kit-8 assay in cells treated with different concentrations of pyrotinib for $48 \mathrm{~h}$. Scale bar, $50 \mu \mathrm{m}$. Data are presented as the mean \pm SD. GC, gastric cancer; BC, breast cancer.
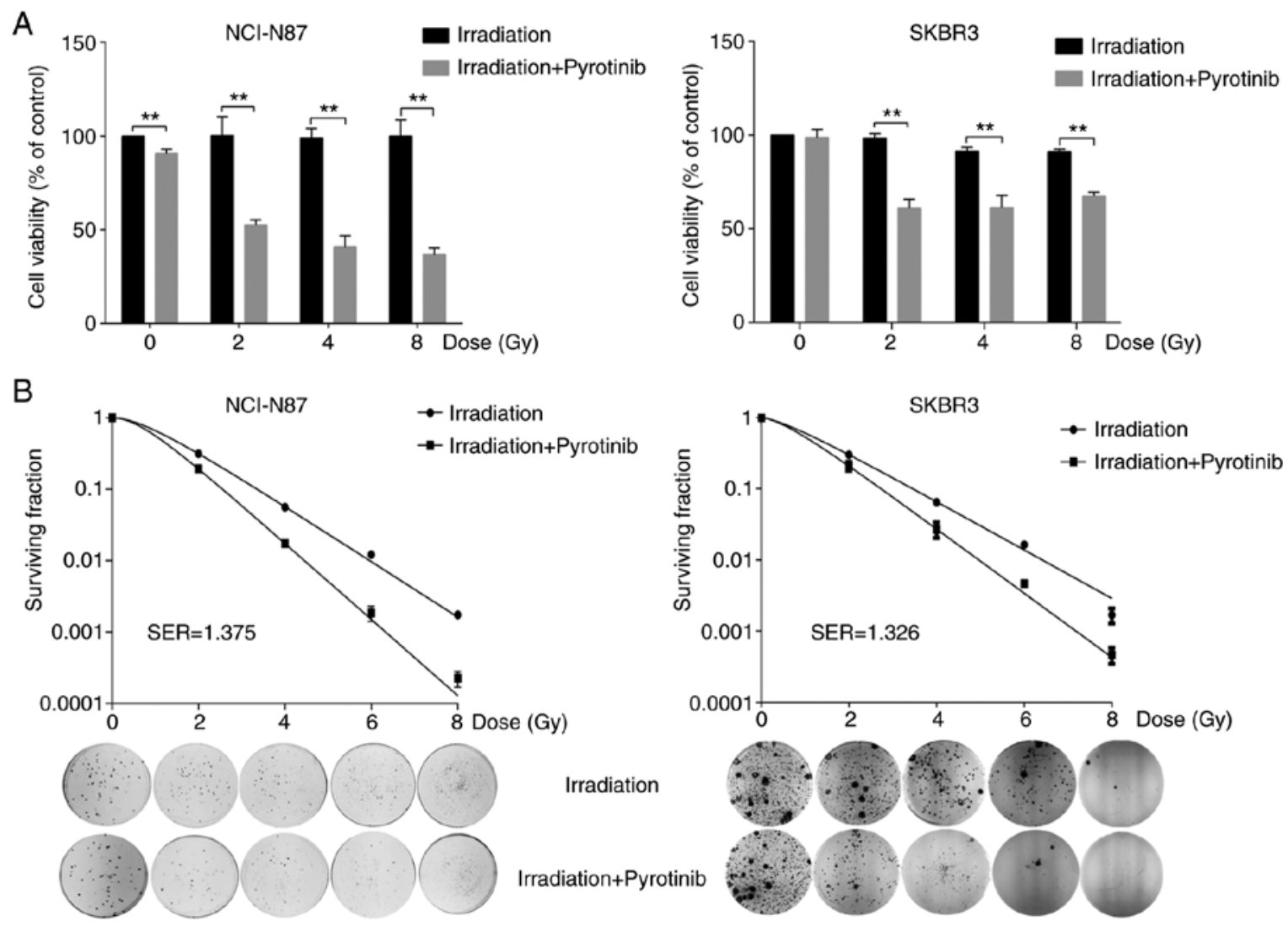

Figure 2. Pyrotinib enhances the radiosensitivity of NCI-N87 and SKBR3 cells. (A) Proliferation was measured using the Cell Counting Kit-8 assay in cells treated with irradiation $(0,2,4$ and $8 \mathrm{~Gy})$ with or without pyrotinib $(0.1 \mu \mathrm{g} / \mathrm{ml})$. (B) NCI-N87 and SKBR3 cells were treated with pyrotinib $(0.1 \mu \mathrm{g} / \mathrm{ml})$ prior to irradiation $(0,2,4,6$ and $8 \mathrm{~Gy})$. Colonies of $>50$ cells were counted after 14 days of culture. SER values of the irradiation group and combined groups were calculated. Data are presented as the mean $\pm \mathrm{SD} .{ }^{* *} \mathrm{P}<0.01$. SER, sensitizer enhancement ratio.

the potential irradiation response of pyrotinib was further examined in vivo. NCI-N87 and SKBR3 cells were used to perform tumor xenograft experiments in athymic nude mice. Following the establishment of the xenograft models, 

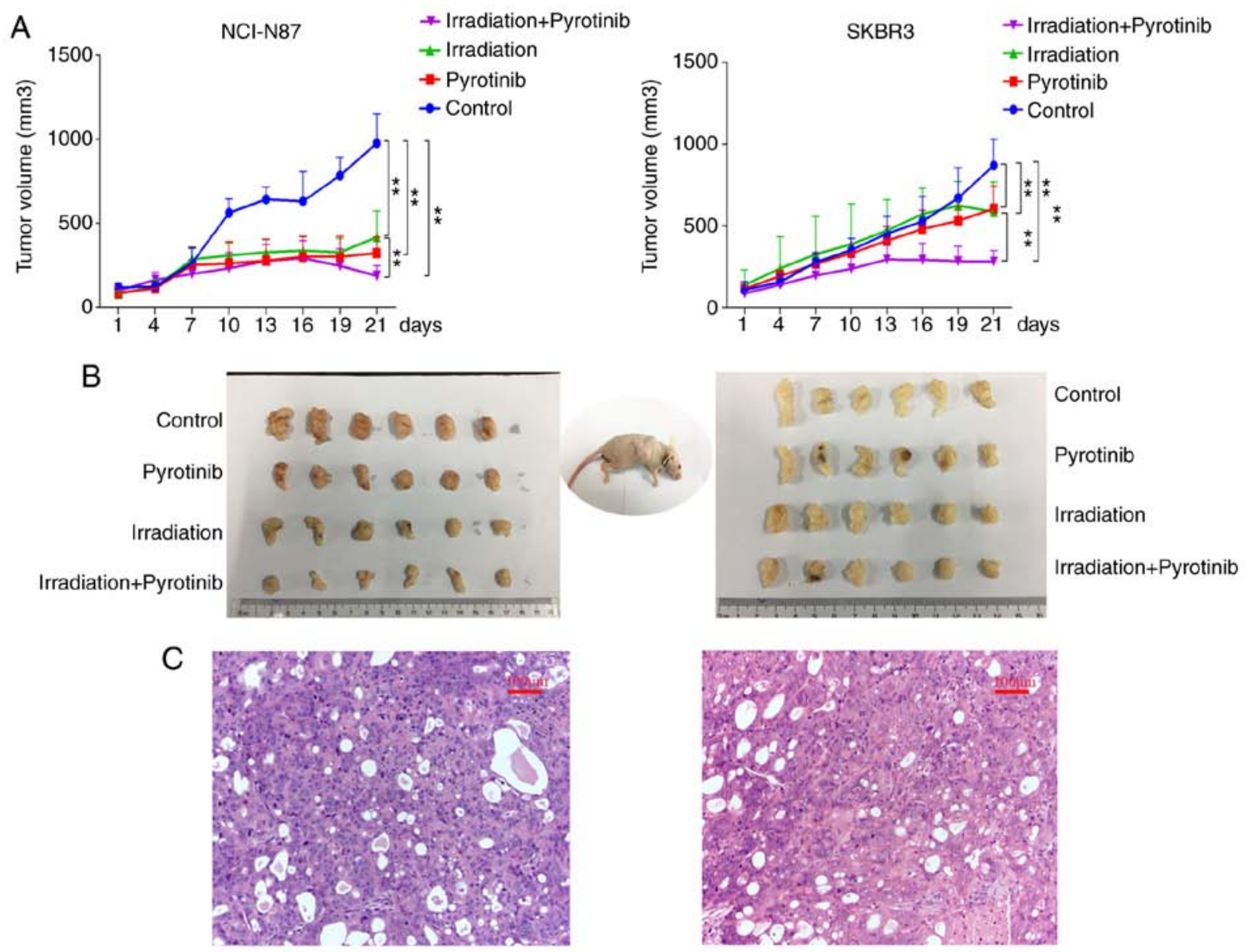

Figure 3. Pyrotinib augments irradiation response in HER2-overexpressing tumor xenografts. Nude mice bearing NCI-N87 or SKBR3 xenografts were randomly divided into four groups: Control group, mice treated with pyrotinib alone, irradiation alone or a combination of pyrotinib and irradiation. (A) Tumor volume was measured thrice weekly for 21 days. (B) Tumors were dissected 21 days after treatment. Representative external appearances of tumor and tumor-bearing mice are presented. (C) Representative images of hematoxylin and eosin staining of xenografts (magnification, $\mathrm{x} 200$ ). Data are presented as the mean $\pm \mathrm{SD}$. ${ }^{* *} \mathrm{P}<0.01$.

different groups of mice were treated with a single-dose of irradiation (10 Gy) alone, pyrotinib (10 $\mathrm{mg} / \mathrm{kg} /$ day) alone or a combination of irradiation and pyrotinib. The antitumor effect of these treatments was determined by measuring the tumor volume (Fig. 3). In both NCI-N87 and SKBR3 xenograft tumors, irradiation combined with pyrotinib demonstrated a greater antitumor effect compared with irradiation alone, although treatment with irradiation or pyrotinib alone treatment also had a significant inhibitory effect on tumor growth. Moreover, the combination strategy did not induce any mortality or a significant decrease in mouse body weight (data not shown), suggesting that pyrotinib may act as an effective and safe RT sensitizer.

Pyrotinib inhibits irradiation-induced HER2 nuclear transport. Following HER2 activation, two main cell signaling pathways, including PI3K/Akt and MEK/MAPK pathways, could be activated involving in the mitogenic and survival signals (7). To assess their involvement in pyrotinib-mediated radiosensitization in the HER2-overexpressing GC and $\mathrm{BC}$ cells, the expression levels of p-Akt and MAPK were examined after irradiation, with or without the pretreatment of pyrotinib. Western blotting results demonstrated that pyrotinib markedly suppressed Akt signaling and exerted no effect on MAPK signaling in irradiated SKBR3 cells. In NCI-N87 cells, pretreatment of pyrotinib before irradiation presented no notable influences on Akt and MAPK signaling (Fig. 4A).

Previous studies have reported that the nuclear transport pathway also contributes to radioresistance, especially HER2 transport from membranes to nuclei $(13,14)$. To examine the influence of pyrotinib on irradiation-induced HER2-nuclear transport, the nuclear protein was extracted at $0,0.25,0.5$, 1 and $6 \mathrm{~h}$ after irradiation, with or without pretreatment of pyrotinib. The expression of HER 2 in nuclear fraction was notably increased after irradiation, attaining a peak at $0.5 \mathrm{~h}$ after irradiation. In NCI-N87 and SKBR3 cells, treatment with pyrotinib before irradiation decreased HER2 expression in the nucleus at different time-points (Fig. 4B). Thus, it was indicated that pyrotinib can decrease the irradiation-induced HER 2 nuclear transport, improving the radiosensitivity of HER2-overexpressing cells.

Pyrotinib increases apoptosis and G2/M arrest induced by irradiation in NCI-N87 cells. To determine whether pyrotinib affected radiosensitivity by inducing apoptosis, flow cytometric analysis was performed. The irradiation dose of 4 Gy was selected, since the irradiation of 4 Gy combined with pyrotinib suppressed cell viability significantly and the survival rate of cancer cells was modest (Fig. 2A). To evaluate the occurrence of apoptosis, NCI-N87 and SKBR3 cells were 
A

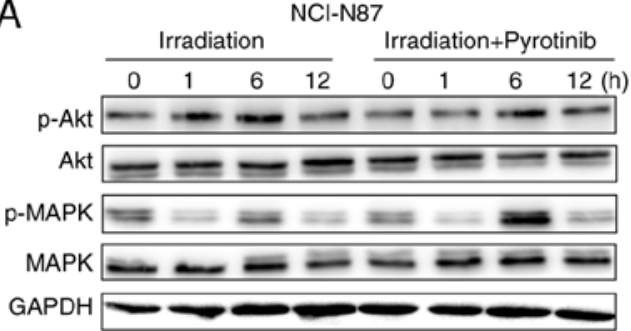

B

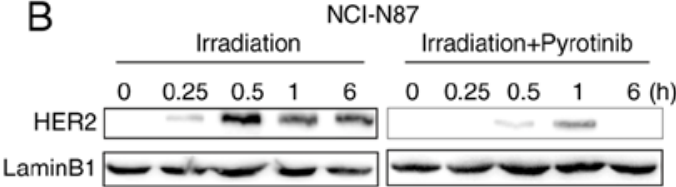

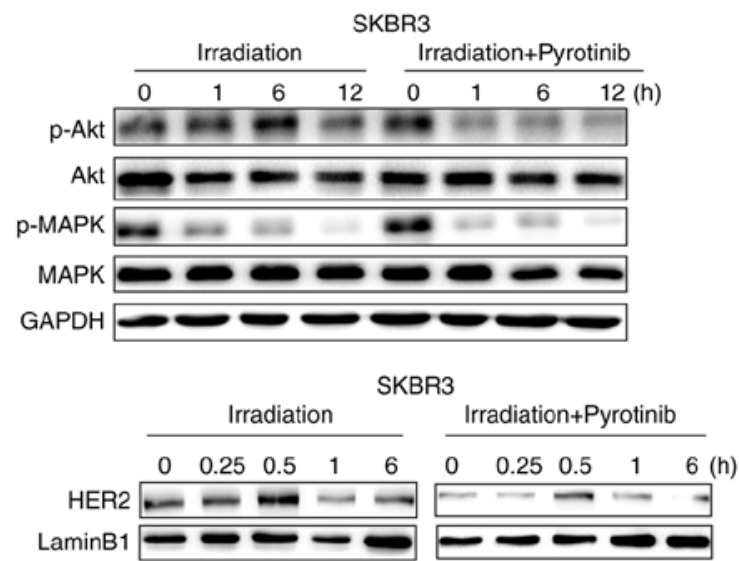

SKBR3
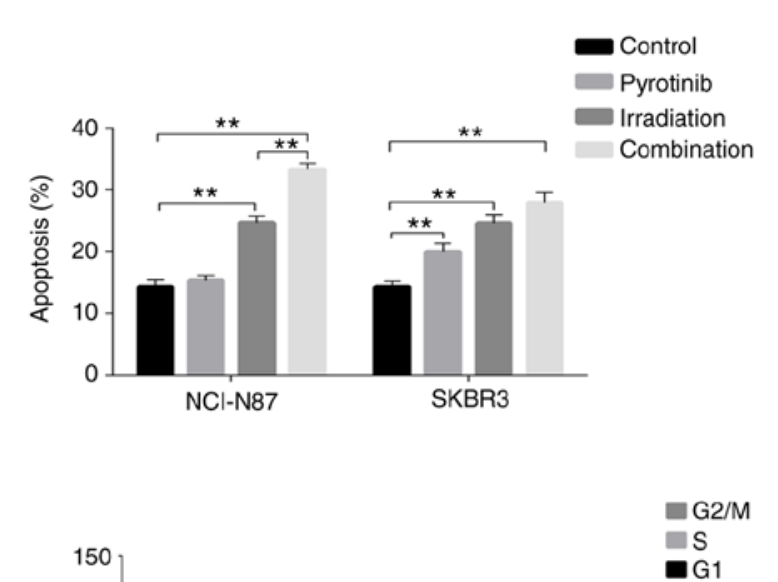

G

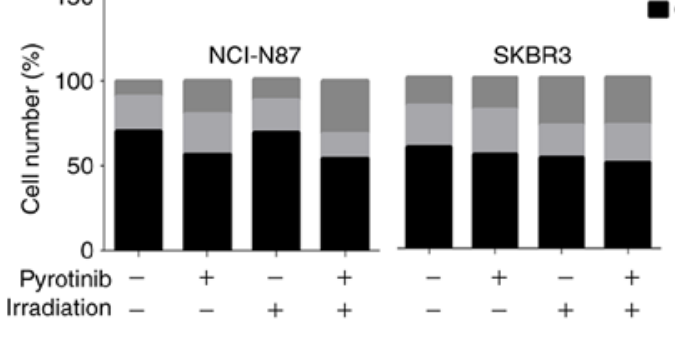

Figure 4. Effects of pyrotinib on the PI3K/Akt and MEK/MAPK pathways, HER2 nuclear transport, apoptosis and cell cycle distribution after irradiation. NCI-N87 and SKBR3 cells were treated with or without pyrotinib $(0.1 \mu \mathrm{g} / \mathrm{ml})$ before irradiation (4 Gy). (A) Protein expression levels of p-Akt, Akt, p-MAPK and MAPK were examined via western blot analysis after irradiation at different time-points. (B) Protein expression of HER2 in the nucleus was tested using western blotting after irradiation at different time-points. Lamin B1 was used as nuclear protein-loading reference control. NCI-N87 and SKBR3 cells were treated with pyrotinib $(0.1 \mu \mathrm{g} / \mathrm{ml})$, irradiation $(4 \mathrm{~Gy})$ or the combination of pyrotinib and irradiation. (C) Apoptosis was assessed at $48 \mathrm{~h}$ after treatment via flow cytometric analysis. (D) Cell distribution in cell cycle phases was evaluated using flow cytometry assay at $48 \mathrm{~h}$ after treatment. Data are presented as the mean $\pm \mathrm{SD} .{ }^{* *} \mathrm{P}<0.01$. p-, phosphorylated.

examined at $48 \mathrm{~h}$ after irradiation (4 Gy), with or without pyrotinib $(0.1 \mu \mathrm{g} / \mathrm{ml})$, suggesting that the combination treatment significantly increased the apoptosis of NCI-N87 cells, but not SKBR3 cells, when compared with the irradiation alone group (Fig. 4C). Treatment with pyrotinib or irradiation alone induced a significant increase of apoptosis in SKBR3 cells in comparison with control group. Additionally, irradiation alone demonstrated a significant increase of apoptosis in NCI-N87 cells. However, pyrotinib alone failed to induce any significant changes of apoptosis in NCI-N87 cells.

The effects of pyrotinib and irradiation alone, or combination on cell cycle progression were examined using flow cytometry (Fig. 4D). Following irradiation, $\mathrm{G}_{2} / \mathrm{M}$ phase cells were increased in the cell cycle distribution of both two cell lines, compared with the control group. Moreover, pyrotinib induced in $\mathrm{G}_{2} / \mathrm{M}$ arrest after irradiation only in NCI-N87 cells. In SKBR3 cells, pyrotinib failed to significantly affect irradiation-induced $\mathrm{G}_{2} / \mathrm{M}$ arrest.

These findings indicated that pyrotinib promotes apoptosis and $\mathrm{G}_{2} / \mathrm{M}$ arrest induced by irradiation, and this may be the additional mechanism via which pyrotinib could overcomes resistance to irradiation in HER2-overexpressing GC and BC.

Pyrotinib inhibits DNA double-strand break (DSB) repair in irradiated HER2-overexpressing GC and BC cells. To further determine the other potential mechanisms of pyrotinib-induced radiosensitivity, the effect of this agent on DSBs repair was investigated. The expression of $\gamma-\mathrm{H} 2 \mathrm{AX}$, a marker of DSBs, was assessed in irradiated NCI-N87 and SKBR3 cells, with or without pretreatment of pyrotinib. Pyrotinib co-treatment markedly enhanced the expression of $\gamma-\mathrm{H} 2 \mathrm{AX}$ compared with irradiated cells $1 \mathrm{~h}$ after irradiation (Fig. 5A and B). 


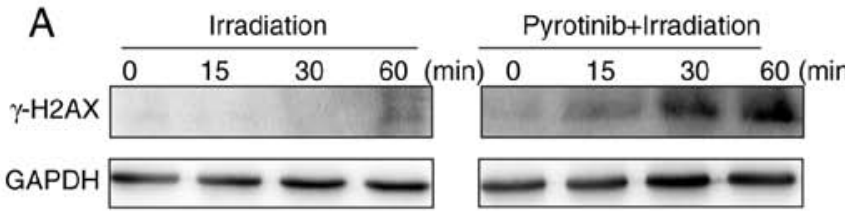

NCl-N87

B
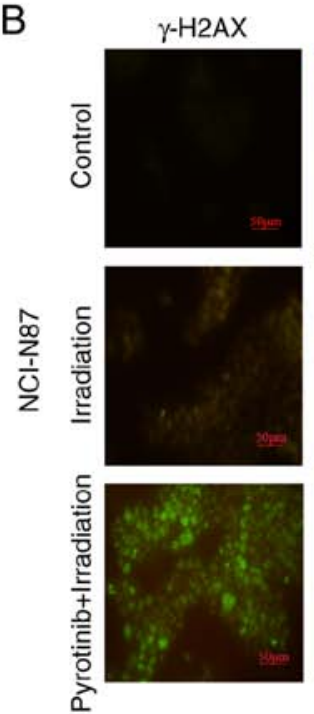

DAPI
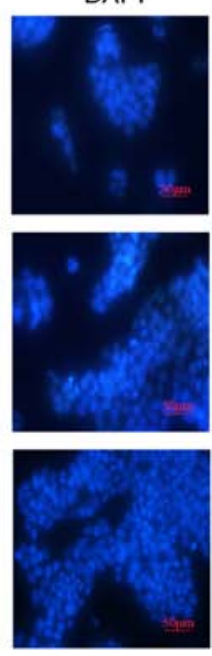
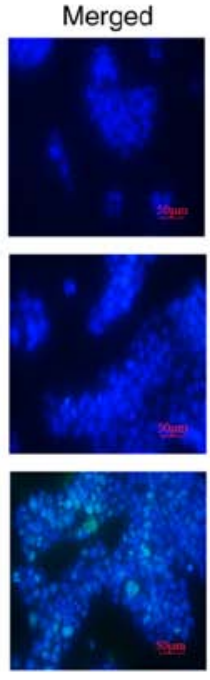

Figure 5. Pyrotinib inhibits DSBs repair in irradiated NCI-N87 and SKBR3 cells. Cells were treated with or without pyrotinib $(0.1 \mu \mathrm{g} / \mathrm{ml} ; 24 \mathrm{~h})$ before irradiated (4 Gy). (A) Expression of $\gamma$-H2AX was measured via western blot analysis at the indicated time-points. (B) Immunofluorescence images illustrating representative $\gamma$-H2AX nuclear foci (green) indicating DSBs of cells. Scale bar, $50 \mu \mathrm{m}$. DSB, double-strand breaks; $\gamma$-H2AX, $\gamma$-H2A histone family member X.

Additionally, $\gamma$-H2AX expression was present for a longer period in NCI-N87 cells compared with in SKBR3 cells. As DSBs repair is a well-established cause of radioresistance (21), these findings suggested that the inhibition of DSBs repair may be a common mechanism via which pyrotinib sensitizes HER2-overexpressing GC and BC cells to irradiation.

Pyrotinib enhances the cytotoxicity of docetaxel in HER2-overexpressing GC and BC cells. To investigate the possible antitumor effects of pyrotinib in combination with docetaxel, fluorouracil, cisplatin or epirubicin, NCI-N87 and SKBR3 cells were exposed to varying concentrations of each agent alone, with or without pyrotinib $(0.1 \mu \mathrm{g} / \mathrm{ml})$ for $48 \mathrm{~h}$. The combination experiments demonstrated that pyrotinib significantly increased the cytotoxicity of docetaxel and cisplatin in NCI-N87 cells (Fig. 6). While in SKBR3 cells, pyrotinib significantly enhanced the cytotoxicity of docetaxel and fluorouracil. It was found that pyrotinib did not increase the cytotoxicity of epirubicin in both cell lines. Overall, the data indicated that pyrotinib sensitized both NCI-N87 and SKBR3 cells to docetaxel.

\section{Discussion}

The present study demonstrated that pyrotinib enhanced the radiosensitivity of HER2-overexpressing GC and BC cells, both in vitro and in vivo. It was suggested that the major mechanism involved in this process was pyrotinib-induced inhibition of HER2 nuclear transport. Additionally, the present findings indicated that pyrotinib was associated with increased DNA damage induced by irradiation. A potent capacity of pyrotinib to augment the cytotoxicity of docetaxel was observed in both
GC and BC cell lines. These data could provide a strategy to improve the response to RT, as well as to select the most efficient drug combination in individual patients.

The present results suggested that inhibition of irradiation-induced HER2 nuclear transport was a crucial mechanism for pyrotinib-enhanced radiosensitivity. Although the mechanism of HER2-induced radioresistance remains unknown, increasing evidence, including data from the current study, reveal the presence and function of HER 2 in the nucleus $(13-20,22)$. Nuclear HER2 positivity has been identified as an independent prognostic factor in patients with BC with membrane HER2-upregulation (23). Reportedly, irradiation can result in HER2 nuclear transport, which may contribute to the radioresistance of cancer types with high HER2 expression (14). In the present study, nuclear HER2 was decreased with pyrotinb treatment in irradiated cells.

The response to irradiation is recognized to be driven by the repair efficacy of irradiation-induced DNA damage, in which DSBs serve a major role (21). Since EGFR can inhibit DNA damage (24), the present study investigated whether pyrotinib suppressed DSB repair in response to irradiation by detecting $\gamma-\mathrm{H} 2 \mathrm{AX}$ expression. $\mathrm{H} 2 \mathrm{AX}$ is rapidly phosphorylated at the site of DSBs and acts as a damage signaling protein forming nuclear foci visible using immunofluorescence (21). Compared with cells treated with irradiation alone, pyrotinib significantly markedly $\gamma$-H2AX expression in NCI-N87 and SKBR3 cells after irradiation, suggesting a failure of DSBs repair. The present findings suggested pyrotinib was associated with increased DNA damage induced by irradiation.

Cancer cell exposure to irradiation results in the activation of the HER family, subsequently stimulating downstream 

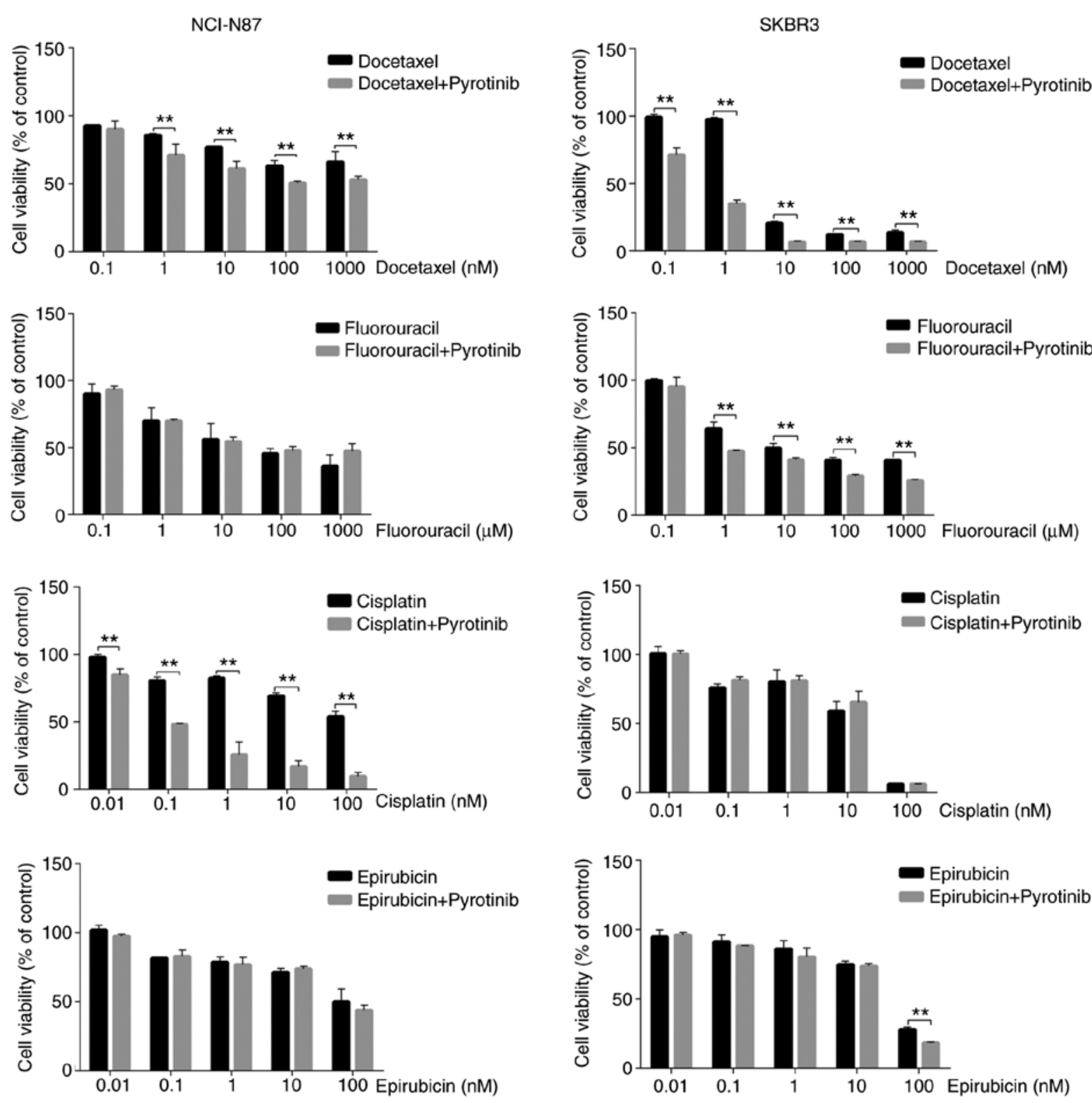

Figure 6. Effects of pyrotinib in combination with docetaxel, fluorouracil, cisplatin or epirubicin in NCI-N87 and SKBR3 cells. Cells were cultured with various concentrations of chemicals alone or combined with pyrotinib $(0.1 \mu \mathrm{g} / \mathrm{ml})$ for $48 \mathrm{~h}$. Cell viability was detected using the Cell Counting Kit- 8 assay. Data are presented as the mean $\pm \mathrm{SD} .{ }^{* *} \mathrm{P}<0.01$.

signaling pathways that regulate cellular processes, including proliferation, apoptosis and cell cycle distribution $(25,26)$. The key mechanism of irradiation-induced cell death is apoptosis (25). In the present study, pyrotinib increased irradiation-induced apoptosis only in NCI-N87 cells. The cell cycle distribution was also analyzed. Compared with irradiation alone, the combination of irradiation and pyrotinib substantially enhanced $\mathrm{G}_{2} / \mathrm{M}$ arrest in NCI-N87 cells. The enhanced radiosensitivity identified in NCI-N87 cells may be attributed to increased apoptosis and $\mathrm{G}_{2} / \mathrm{M}$ arrest, while this was not observed in SKBR3 cells. Genetic heterogeneity between the two cell lines may explain these inconsistent results. However, other factors besides HER2 may participate in the irradiation-induced apoptosis and cell cycle redistribution in BC.

Trastuzumab combined with RT has been widely used in the adjuvant therapy of $\mathrm{BC}(12,27,28)$. The toxicities of RT with concurrent trastuzumab are deemed acceptable and the outcomes were favorable $(27,28)$. A clinical trial provided relevant evidence demonstrating the radiosensitizing effect of trastuzumab in HER2-overexpressing BC (29). However, tumors expressing HER2 may exhibit autocrine stimulation of EGFR/HER1 via expression of one of its numerous ligands including EGF, amphiregulin (AR) and TGF- $\alpha$ (30). Therefore, this type of cooperation may result in the activation of additional intracellular pathways, contributing to tumor progression. In this respect, pyrotinib, an irreversible dual (EGFR/HER2) TKI, has displayed high potency in HER2-dependent cancer cells in vitro and in vivo (20). Previous investigations have reported that irradiated cells may activate HER2 and trigger subsequent signal transduction, including PI3K/Akt and MEK/MAPK pathways $(31,32)$. The enhanced radiosensitivity induced by trastuzumab has been attributed mainly to the inhibition of the PI3K/Akt 


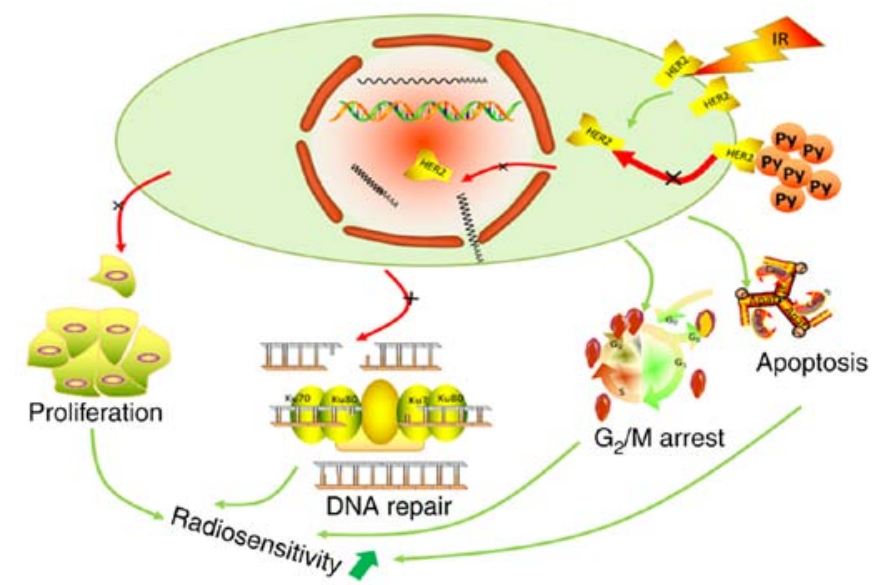

Figure 7. Py enhances the radiosensitivity of HER2-overexpressing GC and BC cells by inhibiting HER2 nuclear transport. Py in combination with IR may increase clonogenic cell death, apoptosis, cell cycle arrest and DNA damage. IR, Irradition; Py, Pyrotinib; Casp9, caspase-9; Apaf, apoptotic protease activating factor.

signal pathway, instead of the MEK/MAPK-mediated signal transduction (11). Consistently, the present study demonstrated that pyrotinib combined with irradiation markedly suppressed p-Akt expression in SKBR3 cells. By contrast, in NCI-N87 cells, pyrotinib did not notably inhibit the PI3K/Akt or MEK/MAPK pathways. Thus, the distinct mechanisms of action and chemical structures of pyrotinib and trastuzumab may induce diverse signal transduction pathways in cancer types.

The current findings support the feasibility of RT combined with pyrotinib in patients with HER2-overexpressing GC and BC. Indeed, neoadjuvant RT may achieve clinical tumor downstaging and increase the possibility of $\mathrm{R} 0$ resection in patients with local advanced GC (33-36). Thus, neoadjuvant RT could be developed as a promising standard treatment for patients with potentially resectable local advanced GC. Since INT-0116 and ARTIST studies were published, postoperative RT has also been utilized in patients with GC $(37,38)$. R1 surgical resection is an indication for postoperative RT. RT is considered as a crucial component of BC therapy and has been recommended in various guidelines (e.g. National Comprehensive Cancer Network; American Society of Clinical Oncology; European Society for Medical Oncology; Chinese Society of Clinical Oncology) for $>20$ years (39-41). In patients harboring regional lymph node metastasis or residual tumor tissue in the chest wall after surgery or systemic therapy, RT can not only decrease the local recurrence rate but also prolong survival time $(42,43)$.

In the present study, the use of sub-cytotoxicity concentration of pyrotinib could increase the cytotoxicity induced by irradiation and the radiosensitivity of tumor tissues, without enhancing the irradiation dose and side effects of RT. Before actual clinical applications, further research is required to assess the feasibility, benefits and adverse reactions of using pyrotinib as a radiosensitizer. The clinical applications of pyrotinib are currently under investigation. For instance, studies into the tolerability, safety and pharmacokinetic properties in humans have been completed (20). The first study (clinical trial no. NCT01937689) of pyrotinib in patients with HER2-positive metastatic BC who previously received treatment with trastuzumab, or were trastuzumab naïve, reported that the median progression-free survival was 35.4 and 59.7 weeks in the 320 and $400 \mathrm{mg}$ dose cohorts, respectively (44). Further investigations of pyrotinib in patients with HER2-positive metastatic BC are ongoing to collect data relating to its safety and efficacy. In addition, the present results suggested that pyrotinib enhanced the cytotoxicity of docetaxel in NCI-N87 and SKBR3 cells, which may provide a novel treatment strategy for HER2-overexpressing GC and BC.

Several limitations of the present study should be mentioned. First, as few GC cell lines overexpress HER2, except NCI-N87, confirmation of HER2 expression in additional GC cell lines would be valuable. Second, the effect of RT in combination with pyrotinib and docetaxel requires further investigation.

In conclusion, to the best of our knowledge, the present findings are the first to suggest that pyrotinib sensitized HER2-overexpressing GC and BC cells to irradiation by inhibiting HER2 nuclear transport. It was identified that DNA damage appeared to serve a crucial role in pyrotinib-induced sensitization of cancer cells to irradiation (Fig. 7). The cytotoxicity of docetaxel was enhanced by pyrotinib in HER2-overexpressing GC and BC cells. However, additional clinical investigations and associated translational studies are required to further understand the current findings.

\section{Acknowledgements}

Not applicable.

\section{Funding}

This work was funded by the National Natural Science Foundation of China (grants nos. 81472921 and 81372664).

\section{Availability of data and materials}

The datasets used and/or analyzed during the current study are available from the corresponding author on reasonable request.

\section{Authors' contributions}

TH wrote the original manuscript and analyzed the data. TH, XL, BW, PP, YD and GH performed the experiments and partial data analysis. YD and $\mathrm{GH}$ revised the original manuscript. HQ and XY designed and revised the research for critical intellectual content. Each author made a significant scientific contribution to the present research and was familiar with the primary data. All listed authors have read the complete manuscript and approved the submission and publication of the paper.

\section{Ethics approval and consent to participate}

Experiments in the present study were executed according to the guidelines of, and were approved by the Ethical Committee of Tongji Hospital, Tongji Medical College, Huazhong University of Science and Technology. 


\section{Patient consent for publication}

Not applicable.

\section{Competing interests}

The authors declare that they have no competing interests.

\section{References}

1. Chen W, Zheng R, Baade PD, Zhang S, Zeng H, Bray F, Jemal A, Yu XQ and He J: Cancer statistics in China, 2015. CA Cancer J Clin 66: 115-132, 2016

2. Valentini V and Cellini F: Radiotherapy in gastric cancer: A systematic review of literature and new perspectives. Expert Rev Anticancer Ther 7: 1379-1393, 2007.

3. Slamon DJ, Clark GM, Wong SG, Levin WJ, Ullrich A and McGuire WL: Human breast cancer: Correlation of relapse and survival with amplification of the HER-2/neu oncogene. Science 235: 177-182, 1987

4. Perez EA and Spano JP: Current and emerging targeted therapies for metastatic breast cancer. Cancer 118: 3014-3025, 2012.

5. Gravalos $\mathrm{C}$ and Jimeno A: HER2 in gastric cancer: A new prognostic factor and a novel therapeutic target. Ann Oncol 19 1523-1529, 2008.

6. Slamon DJ, Godolphin W, Jones LA, Holt JA, Wong SG, Keith DE, Levin WJ, Stuart SG, Udove J, Ullrich A, et al: Studies of the HER-2/neu proto-oncogene in human breast and ovarian cancer. Science 244: 707-712, 1989.

7. No M, Choi EJ and Kim IA: Targeting HER2 signaling pathway for radiosensitization: Alternative strategy for therapeutic resistance. Cancer Biol Ther 8: 2351-2361, 2009.

8. Hou J, Zhou Z, Chen X, Zhao R, Yang Z, Wei N, Ni Q, Feng Y, Yu X, Ma J and Guo X: HER2 reduces breast cancer radiosensitivity by activating focal adhesion kinase in vitro and in vivo. Oncotarget 7: 45186-45198, 2016.

9. Yu T, Cho BJ, Choi EJ, Park JM, Kim DH and Kim IA: Radiosensitizing effect of lapatinib in human epidermal growth factor receptor 2-positive breast cancer cells. Oncotarget 7: 79089-79100, 2016.

10. Tsai YC, Ho PY, Tzen KY, Tuan TF, Liu WL, Cheng AL, Pu YS and Cheng JC: Synergistic blockade of EGFR and HER2 by new-generation EGFR tyrosine kinase inhibitor enhances radiation effect in bladder cancer cells. Mol Cancer Ther 14: 810-820, 2015.

11. Liang K, Lu Y, Jin W, Ang KK, Milas L and Fan Z: Sensitization of breast cancer cells to radiation by trastuzumab. Mol Cancer Ther 2: 1113-1120, 2003.

12. Jacob J, Belin L, Pierga JY, Gobillion A, Vincent-Salomon A, Dendale R, Beuzeboc P, Campana F, Fourquet A and Kirova YM: Concurrent administration of trastuzumab with locoregional breast radiotherapy: Long-term results of a prospective study. Breast Cancer Res Treat 148: 345-353, 2014.

13. Zhang Y, Yu S, Zhuang L, Zheng Z, Chao T and Fu Q: Caveolin-1 is involved in radiation-induced ERBB2 nuclear transport in breast cancer cells. J Huazhong Univ Sci Technolog Med Sci 32: 888-892, 2012

14. Luo B, Yu S, Zhuang L, Xia S, Zhao Z and Rong L: Induction of ERBB2 nuclear transport after radiation in breast cancer cells. J Huazhong Univ Sci Technolog Med Sci 29: 350-353, 2009.

15. Valabrega G, Montemurro F and Aglietta M: Trastuzumab: Mechanism of action, resistance and future perspectives in HER2-overexpressing breast cancer. Ann Oncol 18: 977-984, 2007.

16. Shi H, Zhang W, Zhi Q and Jiang M: Lapatinib resistance in HER $2^{+}$cancers: Latest findings and new concepts on molecular mechanisms. Tumour Biol: Oct 10, 2016 (Epub ahead of print). doi: 10.1007/s13277-016-5467-2

17. Canonici A, Gijsen M, Mullooly M, Bennett R, Bouguern N, Pedersen K, O'Brien NA, Roxanis I, Li JL, Bridge E, et al: Neratinib overcomes trastuzumab resistance in HER2 amplified breast cancer. Oncotarget 4: 1592-1605, 2013

18. Zhu Y, Li L, Zhang G, Wan H, Yang C, Diao X, Chen X, Zhang L and Zhong D: Metabolic characterization of pyrotinib in humans by ultra-performance liquid chromatography/quadrupole time-of-flight mass spectrometry. J Chromatogr B Analyt Technol Biomed Life Sci 1033-1034: 117-127, 2016
19. Sartor CI: Epidermal growth factor family receptors and inhibitors: Radiation response modulators. Semin Radiat Oncol 13: 22-30, 2003

20. Li X, Yang C, Wan H, Zhang G, Feng J, Zhang L, Chen X, Zhong D, Lou L, Tao W and Zhang L: Discovery and development of pyrotinib: A novel irreversible EGFR/HER2 dual tyrosine kinase inhibitor with favorable safety profiles for the treatment of breast cancer. Eur J Pharm Sci 110: 51-61, 2017.

21. Khanna KK and Jackson SP: DNA double-strand breaks: Signaling, repair and the cancer connection. Nat Genet 27: 247-254, 2001 .

22. Cordo Russo RI, Béguelin W, Díaz Flaqué MC, Proietti CJ, Venturutti L, Galigniana N, Tkach M, Guzmán P, Roa JC, O'Brien NA, et al: Targeting ErbB-2 nuclear localization and function inhibits breast cancer growth and overcomes trastuzumab resistance. Oncogene 34: 3413-3428, 2015.

23. Schillaci R, Guzmán P, Cayrol F, Beguelin W, Diaz Flaque MC, Proietti CJ, Pineda V, Palazzi J, Frahm I, Charreau EH, et al: Clinical relevance of ErbB-2/HER2 nuclear expression in breast cancer. BMC Cancer 12: 74, 2012.

24. Huang SM and Harari PM: Modulation of radiation response after epidermal growth factor receptor blockade in squamous cell carcinomas: Inhibition of damage repair, cell cycle kinetics, and tumor angiogenesis. Clin Cancer Res 6: 2166-2174, 2000.

25. Ethier SP and Lawrence TS: Epidermal growth factor receptor signaling and response of cancer cells to ionizing radiation. J Natl Cancer Inst 93: 890-891, 2001.

26. Dent P, Yacoub A, Contessa J, Caron R, Amorino G, Valerie K, Hagan MP, Grant S and Schmidt-Ullrich R: Stress and radiation-induced activation of multiple intracellular signaling pathways. Radiat Res 159: 283-300, 2003.

27. Halyard MY, Pisansky TM, Dueck AC, Suman V, Pierce L, Solin L, Marks L, Davidson N, Martino S, Kaufman P, et al: Radiotherapy and adjuvant trastuzumab in operable breast cancer: Tolerability and adverse event data from the NCCTG Phase III Trial N9831. J Clin Oncol 27: 2638-2644, 2009.

28. Belkacémi Y, Gligorov J, Ozsahin M, Marsiglia H, De Lafontan B, Laharie-Mineur H, Aimard L, Antoine EC, Cutuli B, Namer M and Azria D: Concurrent trastuzumab with adjuvant radiotherapy in HER2-positive breast cancer patients: Acute toxicity analyses from the French multicentric study. Ann Oncol 19: 1110-1116, 2008

29. Horton JK, Halle J, Ferraro M, Carey L, Moore DT, Ollila D and Sartor CI: Radiosensitization of chemotherapy-refractory, locally advanced or locally recurrent breast cancer with trastuzumab: A phase II trial. Int J Radiat Oncol Biol Phys 76: 998-1004, 2010

30. Olayioye MA, Neve RM, Lane HA and Hynes NE: The ErbB signaling network: Receptor heterodimerization in development and cancer. EMBO J 19: 3159-3167, 2000

31. Contessa JN, Hampton J, Lammering G, Mikkelsen RB, Dent P, Valerie $\mathrm{K}$ and Schmidt-Ullrich RK: Ionizing radiation activates Erb-B receptor dependent Akt and p70 S6 kinase signaling in carcinoma cells. Oncogene 21: 4032-4041, 2002.

32. Bowers G, Reardon D, Hewitt T, Dent P, Mikkelsen RB, Valerie K, Lammering G, Amir C and Schmidt-Ullrich RK: The relative role of ErbB1-4 receptor tyrosine kinases in radiation signal transduction responses of human carcinoma cells. Oncogene 20: 1388-1397, 2001.

33. Trip AK, Poppema BJ, van Berge Henegouwen MI, Siemerink E, Beukema JC, Verheij M, Plukker JT, Richel DJ, Hulshof MC, van Sandick JW, et al: Preoperative chemoradiotherapy in locally advanced gastric cancer, a phase I/II feasibility and efficacy study. Radiother Oncol 112: 284-288, 2014

34. Ajani JA, Winter K, Okawara GS, Donohue JH, Pisters PW, Crane CH, Greskovich JF, Anne PR, Bradley JD, Willett C and Rich TA: Phase II trial of preoperative chemoradiation in patients with localized gastric adenocarcinoma (RTOG 9904): Quality of combined modality therapy and pathologic response. J Clin Oncol 24: 3953-3958, 2006.

35. Ajani JA, Mansfield PF, Janjan N, Morris J, Pisters PW, Lynch PM, Feig B, Myerson R, Nivers R, Cohen DS and Gunderson LL: Multi-institutional trial of preoperative chemoradiotherapy in patients with potentially resectable gastric carcinoma. J Clin Oncol 22: 2774-2780, 2004.

36. Newton AD, Datta J, Loaiza-Bonilla A, Karakousis GC and Roses RE: Neoadjuvant therapy for gastric cancer: Current evidence and future directions. J Gastrointest Oncol 6: $534-543,2015$ 
37. Smalley SR, Benedetti JK, Haller DG, Hundahl SA, Estes NC, Ajani JA, Gunderson LL, Goldman B, Martenson JA, Jessup JM, et al: Updated analysis of SWOG-directed intergroup study 0116: A phase III trial of adjuvant radiochemotherapy versus observation after curative gastric cancer resection. J Clin Oncol 30: 2327-2333, 2012.

38. Park SH, Sohn TS, Lee J, Lim DH, Hong ME, Kim KM, Sohn I, Jung SH, Choi MG, Lee JH, et al: Phase III trial to compare adjuvant chemotherapy with capecitabine and cisplatin versus concurrent chemoradiotherapy in gastric cancer: Final report of the adjuvant chemoradiotherapy in stomach tumors trial, including survival and subset analyses. J Clin Oncol 33: 3130-3136, 2015.

39. Fisher B, Anderson S, Bryant J, Margolese RG, Deutsch M, Fisher ER, Jeong JH and Wolmark N: Twenty-year follow-up of a randomized trial comparing total mastectomy, lumpectomy, and lumpectomy plus irradiation for the treatment of invasive breast cancer. N Engl J Med 347: 1233-1241, 2002.

40. Clarke M, Collins R, Darby S, Davies C, Elphinstone P, Evans V, Godwin J, Gray R, Hicks C, James S, et al: Effects of radiotherapy and of differences in the extent of surgery for early breas cancer on local recurrence and 15-year survival: An overview of the randomised trials. Lancet 366: 2087-2106, 2005.
41. Early Breast Cancer Trialists' Collaborative Group (EBCTCG), Darby S, McGale P, Correa C, Taylor C, Arriagada R, Clarke M, Cutter D, Davies C, Ewertz M, Godwin J, et al: Effect of radiotherapy after breast-conserving surgery on 10-year recurrence and 15-year breast cancer death: Meta-analysis of individual patient data for 10,801 women in 17 randomised trials. Lancet 378: 1707-1716, 2011.

42. Van de Steene J, Soete G and Storme G: Adjuvant radiotherapy for breast cancer significantly improves overall survival: The missing link. Radiother Oncol 55: 263-272, 2000.

43. Ragaz J, Olivotto IA, Spinelli JJ, Phillips N, Jackson SM, Wilson KS, Knowling MA, Coppin CM, Weir L, Gelmon K, et al: Locoregional radiation therapy in patients with high-risk breast cancer receiving adjuvant chemotherapy: 20-year results of the British Columbia randomized trial. J Natl Cancer Inst 97: 116-126, 2005.

44. Ma F, Li Q, Chen S, Zhu W, Fan Y, Wang J, Luo Y, Xing P, Lan B, Li M, et al: Phase I study and biomarker analysis of pyrotinib, a novel irreversible Pan-ErbB receptor tyrosine kinase inhibitor, in patients with human epidermal growth factor receptor 2-positive metastatic breast cancer. J Clin Oncol 35: 3105-3112, 2017. International (CC BY-NC-ND 4.0) License. 